\title{
(6) OPEN ACCESS \\ Unintentional drowning mortality, by age and body of water: an analysis of 60 countries
}

\author{
Ching-Yih Lin, ${ }^{1,2}$ Yi-Fong Wang, ${ }^{2}$ Tsung-Hsueh Lu, ${ }^{3}$ Ichiro Kawach $^{4}$
}

\begin{abstract}
- Additional material is published online only. To view please visit the journal online (http://dx.doi.org/10.1136/ injuryprev-2013-041110).

${ }^{1}$ Department of Internal Medicine, Chi Mei Medical Center, Tainan, Taiwan ${ }^{2}$ Department of Leisure, Recreation, and Tourism Management, Southern Taiwan University of Science and Technology, Tainan, Taiwan ${ }^{3}$ NCKU Research Center for Health Data, National Cheng Kung University, Tainan, Taiwan

${ }^{4}$ Department of Social \& Behavioral Sciences, Harvard School of Public Health, Harvard University, Boston, Massachusetts, USA
\end{abstract}

\section{Correspondence to} Dr Tsung-Hsueh Lu, Department of Public Health, College of Medicine, National Cheng Kung University, No. 1, Dah Hsueh Road, Tainan 701, Taiwan;

robertlu@mail.ncku.edu.tw

Received 26 November 2013 Revised 14 April 2014 Accepted 26 May 2014 Published Online First 18 June 2014

\section{ABSTRACT \\ Background To examine unintentional drowning} mortality by age and body of water across 60 countries, to provide a starting point for further in-depth investigations within individual countries.

Methods The latest available three years of mortality data for each country were extracted from WHO Health Statistics and Information Services (updated at 13 November 2013). We calculated mortality rate of unintentional drowning by age group for each country. For countries using International Classification of Disease 10 (ICD-10) detailed 3 or 4 Character List, we further examined the body of water involved.

Results A huge variation in age-standardised mortality rate (deaths per 100000 population) was noted, from 0.12 in Turkey to 9.19 in Guyana. Of the ten countries with the highest age-standardised mortality rate, six (Belarus, Lithuania, Latvia, Russia, Ukraine and Moldova) were in Eastern Europe and two (Kazakhstan and Kyrgyzstan) were in Central Asia. Some countries (Japan, Finland and Greece) had a relatively low rank in mortality rate among children aged $0-4$ years, but had a high rank in mortality rate among older adults. On the contrary, South Africa and Colombia had a relatively high rank among children aged $0-4$ years, but had a relatively low rank in mortality rate among older adults. With regard to body of water involved, the proportion involving a bathtub was extremely high in Japan (65\%) followed by Canada (11\%) and the USA (11\%). Of the 13634 drowning deaths involving bathtubs in Japan between 2009 and 2011, 12038 (88\%) were older adults aged 65 years or above. The percentage involving a swimming pool was high in the USA (18\%), Australia (13\%), and New Zealand (7\%). The proportion involving natural water was high in Finland (93\%), Panama (87\%), and Lithuania (85\%).

Conclusions After considering the completeness of reporting and quality of classifying drowning deaths across countries, we conclude that drowning is a highpriority public health problem in Eastern Europe, Central Asia, Japan (older adults involving bathtubs), and the USA (involving swimming pools).

\section{INTRODUCTION}

Despite the global decrease of age-standardised unintentional drowning mortality rate from 7.5 (deaths per 100000 population) in 1990 to 5.1 in 2010, there was still a total of 439100 unintentional drowning deaths globally in 2010, according to the Global Burden of Disease Study 2010 (GBD 2010). ${ }^{1}$ Of 439100 estimated unintentional drowning deaths in 2010, one-third (32.1\%) were children aged $0-14$ years, and one-fifth (21.5\%) were young adults aged $25-44$ years. The drowning death rate differed by age group: 12.6 (deaths per
100000 population) for children aged $1-4$ years, 3.0 for early adolescents aged 10-14 years, 5.0 for late adolescents aged 15-19 years, 3.8 for adults aged 44-49 years, and 7.5 for older adults aged $70-75$ years. $^{1}$ For years of life lost, unintentional drowning ranked 21 among 179 causes of death globally; however, the rank was 12 in Eastern and Central Asia and 54 in Western Europe. ${ }^{1}$ However, the GBD 2010 did not analyse drowning deaths by body of water. ${ }^{1}$ The GBD found huge variations in unintentional drowning mortality by age and region, which are mainly due to exposure to different bodies of water (eg, bathtub, swimming pool, pond, lake, stream, river, or beach), activities (eg, activities of daily living, recreation, or work-related activities), and circumstances (eg, after drinking alcohol, during a flood, or the occurrence of diseases, such as epilepsy). ${ }^{2}$

Brenner and Taneja suggest that delineation of location and circumstances surrounding the drowning event are key to identifying prevention strategies. ${ }^{3}$ While there have been many epidemiological studies on locations and circumstances surrounding drowning deaths, most of these studies were confined to a single country. Furthermore, most of these studies focused on children, ${ }^{4-18}$ which cannot help us understand the worldwide diversity of drowning mortality rates. In regards to international comparisons, we found only two. One study examined drowning mortality worldwide, but this study did not present the agespecific drowning mortality rate in each country. ${ }^{19}$ Another recent report revealed a detailed picture of drowning mortality rates among children in lowincome and middle-income counties in Asia. ${ }^{20}$ However, no study yet has compared unintentional drowning mortality rates in middle and older adults across countries. International comparisons of injury mortality can help generate hypotheses and provide clues for injury prevention. ${ }^{21-24}$ Thus, we sought to examine unintentional drowning mortality by age and body of water across countries to provide a starting point for further in-depth investigations of unintentional drowning mortality within individual countries.

\section{METHODS}

\section{Data source}

Mortality data for each country were extracted from the WHO Health Statistics and Health Information Services. ${ }^{25}$ As of 13 November 2013, 153 countries had submitted mortality data to WHO. Because we are interested in relatively current comparisons, we excluded countries for which the latest available data was before 2005 . 
Table 1 Ranking of unintentional drowning mortality rates for each country by different age groups

\begin{tabular}{|c|c|c|c|c|c|c|c|}
\hline Country, latest available 3 years & All ages & $0-4$ & $5-14$ & $15-24$ & $25-44$ & $45-64$ & $65+$ \\
\hline Guyana, 2006-2008 & 1 & 3 & 15 & 1 & 4 & 2 & 2 \\
\hline Belarus, 2007-2009 & 2 & 16 & 8 & 2 & 1 & 4 & 4 \\
\hline Lithuania, 2008-2010 & 3 & 8 & 6 & 4 & 3 & 1 & 5 \\
\hline Latvia, 2008-2010 & 4 & 10 & 9 & 3 & 7 & 3 & 7 \\
\hline Russia, 2008-2010 & 5 & 14 & 5 & 5 & 2 & 5 & 12 \\
\hline Thailand, 2004-2006 & 6 & 2 & 1 & 12 & 10 & 9 & 6 \\
\hline Kazakhstan, 2008-2010 & 7 & 4 & 3 & 6 & 5 & 11 & 23 \\
\hline Ukraine, 2009-2011 & 8 & 17 & 4 & 7 & 6 & 8 & 13 \\
\hline Moldova, 2009-2011 & 9 & 12 & 2 & 15 & 8 & 6 & 10 \\
\hline Kyrgyzstan, 2008-2010 & 10 & 1 & 12 & 20 & 9 & 10 & 8 \\
\hline Estonia, 2009-2011 & 11 & 23 & 25 & 11 & 12 & 7 & 14 \\
\hline El Salvador, 2007-2009 & 12 & 22 & 16 & 8 & 11 & 14 & 33 \\
\hline Romania, 2008-2010 & 13 & 28 & 7 & 17 & 16 & 12 & 11 \\
\hline Panama, 2007-2009 & 14 & 5 & 11 & 9 & 14 & 21 & 15 \\
\hline Nicaragua, 2008-2010 & 15 & 32 & 27 & 10 & 13 & 18 & 32 \\
\hline Brazil, 2008-2010 & 16 & 13 & 13 & 14 & 15 & 22 & 39 \\
\hline Ecuador, 2008-2010 & 17 & 6 & 14 & 16 & 18 & 31 & 19 \\
\hline Japan, 2009-2011 & 18 & 43 & 42 & 47 & 49 & 23 & 1 \\
\hline Uruguay, 2007-2009 & 19 & 25 & 17 & 13 & 20 & 27 & 27 \\
\hline Chile, 2007-2009 & 20 & 19 & 33 & 26 & 17 & 17 & 20 \\
\hline South Africa, 2007-2009 & 21 & 7 & 10 & 28 & 23 & 34 & 25 \\
\hline Slovakia, 2008-2010 & 22 & 35 & 26 & 29 & 19 & 15 & 18 \\
\hline Costa Rica, 2007-2009 & 23 & 27 & 22 & 22 & 21 & 20 & 34 \\
\hline Finland, 2009-2011 & 24 & 48 & 50 & 45 & 28 & 13 & 9 \\
\hline Greece, 2008-2010 & 25 & 40 & 46 & 38 & 27 & 26 & 3 \\
\hline Paraguay, 2007-2009 & 26 & 29 & 28 & 18 & 25 & 30 & 45 \\
\hline Colombia, 2007-2009 & 27 & 9 & 18 & 23 & 32 & 42 & 31 \\
\hline Mexico, 2008-2010 & 28 & 21 & 29 & 19 & 24 & 37 & 28 \\
\hline Poland, 2009-2011 & 29 & 50 & 38 & 27 & 26 & 16 & 36 \\
\hline Venezuela, 2005-2007 & 30 & 11 & 19 & 21 & 31 & 40 & 43 \\
\hline Cuba, 2008-2010 & 31 & 31 & 24 & 25 & 22 & 33 & 42 \\
\hline New Zealand, 2007-2009 & 32 & 24 & 47 & 31 & 30 & 29 & 41 \\
\hline Bulgaria, 2009-2011 & 33 & 49 & 20 & 37 & 34 & 28 & 29 \\
\hline Croatia, 2009-2011 & 34 & 59 & 48 & 43 & 38 & 19 & 16 \\
\hline Peru, 2005-2007 & 35 & 18 & 34 & 32 & 35 & 39 & 26 \\
\hline Czech Republic, 2009-2011 & 36 & 36 & 40 & 39 & 33 & 25 & 24 \\
\hline Taiwan, 2009-2011 & 37 & 37 & 31 & 44 & 39 & 35 & 17 \\
\hline Hungary, 2009-2011 & 38 & 55 & 36 & 34 & 36 & 24 & 35 \\
\hline Egypt, 2009-2011 & 39 & 20 & 23 & 24 & 41 & 52 & 57 \\
\hline Norway, 2009-2011 & 40 & 51 & 43 & 33 & 37 & 32 & 37 \\
\hline Argentina, 2008-2010 & 41 & 15 & 32 & 30 & 45 & 50 & 54 \\
\hline France, 2007-2009 & 42 & 34 & 49 & 51 & 43 & 36 & 22 \\
\hline USA, 2008-2010 & 43 & 26 & 41 & 36 & 42 & 43 & 47 \\
\hline Georgia, 2007, 2009, 2010 & 44 & 57 & 35 & 48 & 29 & 44 & 46 \\
\hline Korea, 2009-2011 & 45 & 52 & 37 & 50 & 46 & 38 & 21 \\
\hline Australia, 2009-2011 & 46 & 30 & 44 & 46 & 40 & 51 & 44 \\
\hline Malaysia, 2006-2008 & 47 & 33 & 21 & 40 & 44 & 55 & 58 \\
\hline Serbia, 2009-2011 & 48 & 54 & 30 & 42 & 51 & 41 & 40 \\
\hline Guatemala, 2006-2008 & 49 & 47 & 39 & 35 & 48 & 46 & 56 \\
\hline Canada, 2007-2009 & 50 & 38 & 45 & 41 & 47 & 48 & 50 \\
\hline Spain, 2008-2010 & 51 & 41 & 54 & 49 & 50 & 47 & 38 \\
\hline Sweden, 2008-2010 & 52 & 53 & 53 & 56 & 52 & 45 & 30 \\
\hline Portugal, 2009-2011 & 53 & 39 & 52 & 53 & 54 & 53 & 52 \\
\hline Italy, 2008-2010 & 54 & 58 & 51 & 52 & 53 & 56 & 51 \\
\hline Belgium, 2007-2009 & 55 & 42 & 55 & 59 & 56 & 49 & 49 \\
\hline Austria, 2009-2011 & 56 & 46 & 59 & 54 & 58 & 54 & 48 \\
\hline Netherlands, 2009-2011 & 57 & 45 & 57 & 57 & 57 & 57 & 55 \\
\hline UK, 2008-2010 & 58 & 56 & 58 & 55 & 55 & 58 & 59 \\
\hline Germany, 2009-2011 & 59 & 44 & 56 & 58 & 59 & 59 & 53 \\
\hline Turkey, 2006-2008 & 60 & 60 & 60 & 60 & 60 & 60 & 60 \\
\hline
\end{tabular}


Different countries used different Revision and Tabulation List of the International Classification of Disease (ICD). We used ICD-8 condensed A List A143 (ie, detailed ICD-8 code E910), ICD-9 condensed Basic Tabulation List B521 (ie, detailed ICD-9 code E910), ICD-10 condensed Tabulation List 11098 (ie, detailed ICD-10 codes W65-W74), and ICD-10 detailed Three and Four Character List ICD-10 codes V90, V92, W65W74 to identify unintentional drowning deaths.

To ensure statistical stability in calculating the mortality rate by age group, we combined data for the latest available 3 years, and included only those countries that reported more than 150 unintentional drowning deaths for all age groups. Based on these inclusion criteria, a total of 60 countries were included in the final analysis.

One country (Turkey) used condensed ICD-8 List A; one country (Greece) used condensed ICD-9 Basic Tabulation List; four countries (Kazakhstan, Belarus, Russia, and Ukraine) used condensed ICD-10 Tabulation List 1; seven countries (South
Korea, Malaysia, Taiwan, Bulgaria, Serbia, Egypt, South Africa) used detailed Three Character List ICD-10 codes; and the remaining 47 countries used detailed ICD-10 Four Characters List codes.

Completeness and quality of mortality data differed across countries; because this affects interpretation of this study, we listed the completeness of mortality data for each country as assessed by the WHO. ${ }^{26}$ There were nine countries for which the completeness of mortality data was less than $90 \%$, and seven countries for which the information on completeness was not available (Appendix). For countries that used detailed ICD-10 Three or Four Character List codes, we further examined the quality of reporting for body of water (ie, bathtub, swimming pool, natural water, other) and mechanism (while in water or falling into water). To do this, we calculated the percentage of drowning deaths classified as 'unspecified' (ICD-10 code W74) among all drowning deaths (ICD-10 codes W65-W74). We defined 'high quality' data as having less than

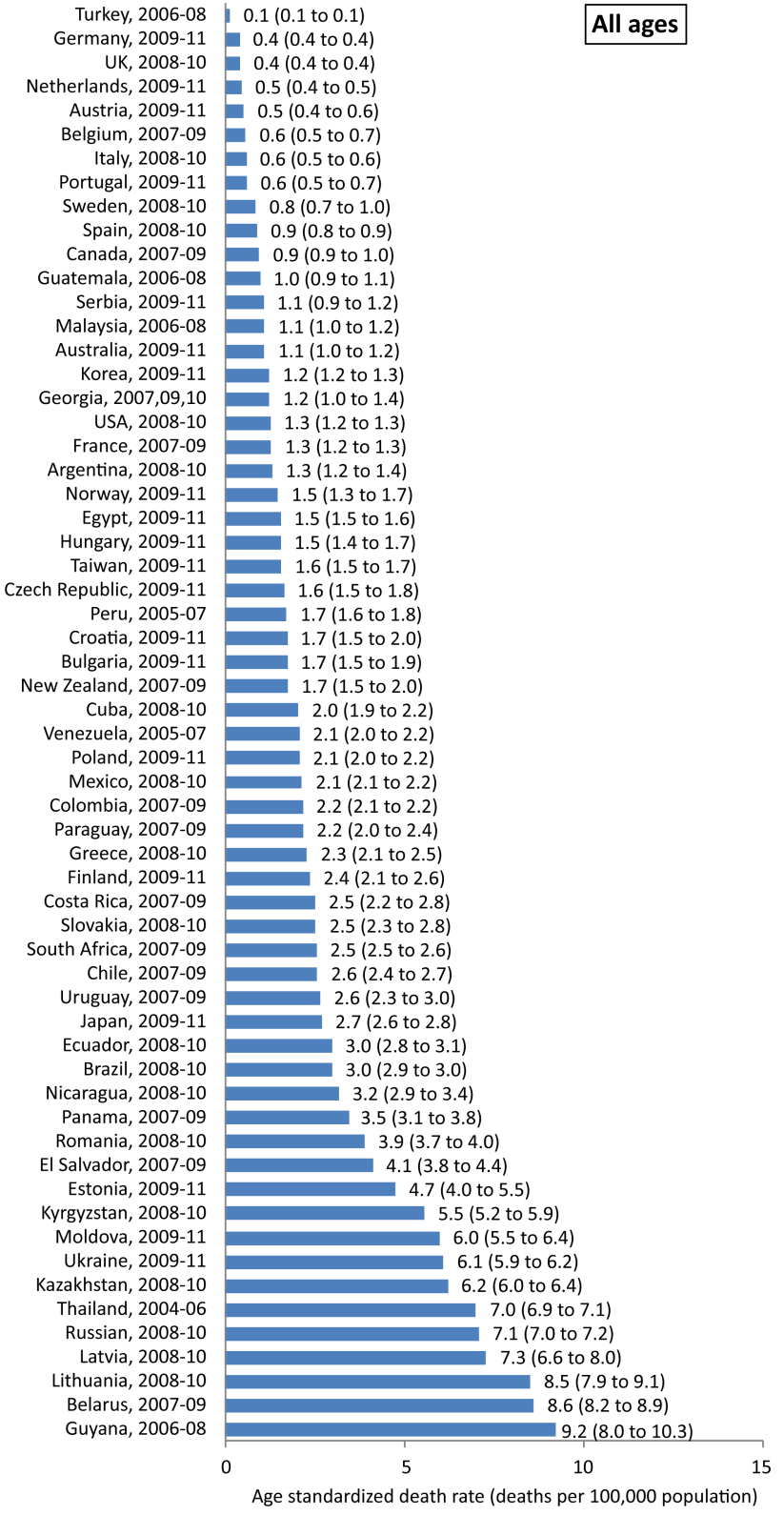

Figure 1 The age-standardised unintentional drowning mortalty rate (deaths per 100000 population) and 95\% Cls in each country.

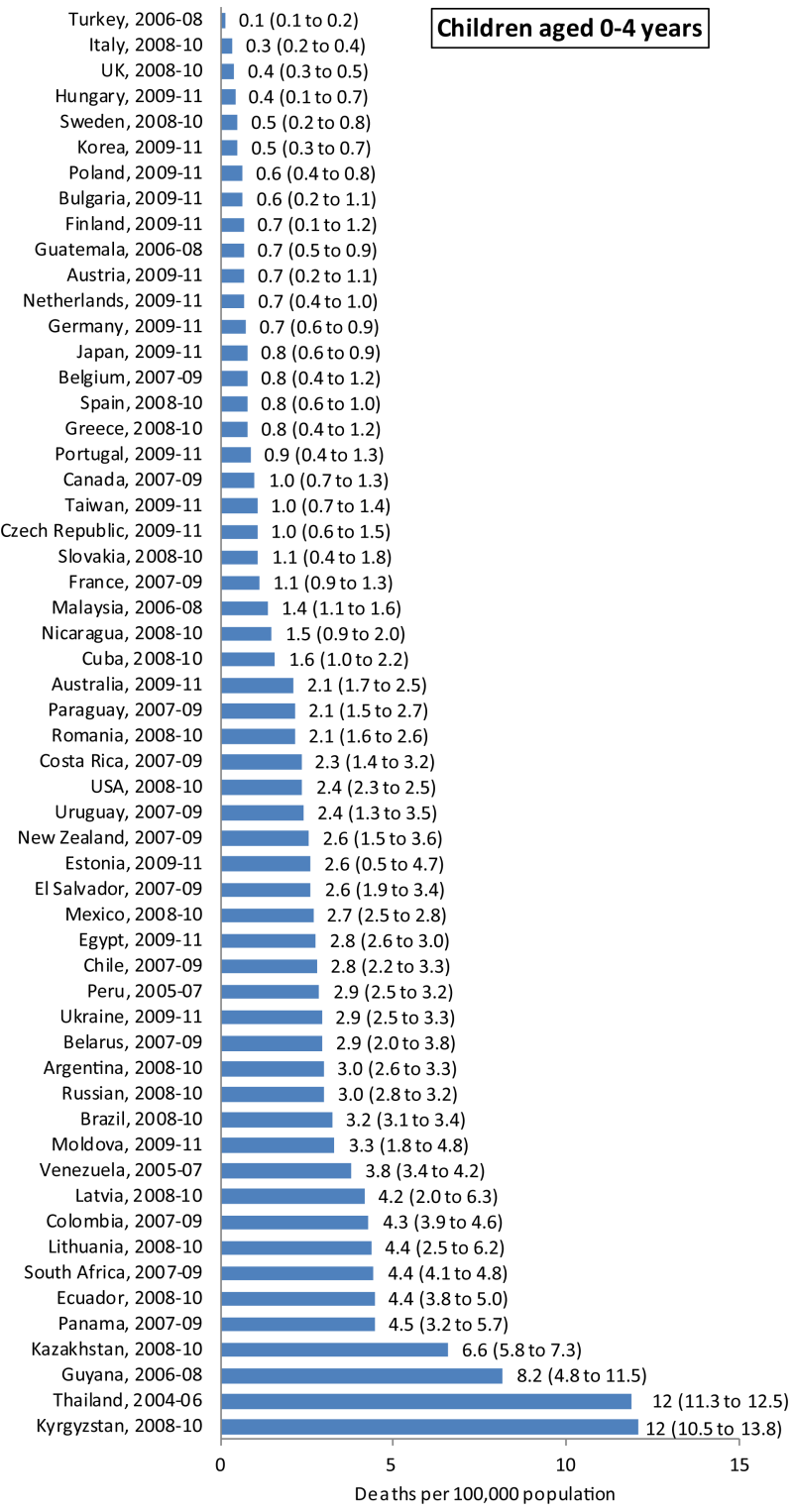

Figure 2 Unintentional drowning mortalty rate (deaths per 100000 population) and $95 \% \mathrm{Cls}$ for children aged $0-4$ years in each country. 
$20 \%$ as 'unspecified', as suggested by the Global Burden of Disease Injury Expert Group. ${ }^{27}$

\section{Statistical analysis}

We first calculated the age-specific (0-4, 5-14 15-24, 25-44, 4564 , and $65+$ years) unintentional drowning mortality rates (deaths per 100000 population) and 95\% CIs in each country and region. Some countries did not provide population data to WHO, so we used population data from the 2010 Revision of the World Population Prospects undertaken by the Population Division of the United Nations Department of Economic and Social Affairs of the United Nations Secretariat. ${ }^{28}$ We used the WHO World Standard Population to compute the age-standardised mortality rate. ${ }^{25}$ We then ranked the unintentional drowning mortality rates of each country by age groups. For countries that used detailed ICD-10 Three or Four Character List codes, we further illustrated the percentage of drowning deaths by body of water (ie, bathtub, swimming pool, natural

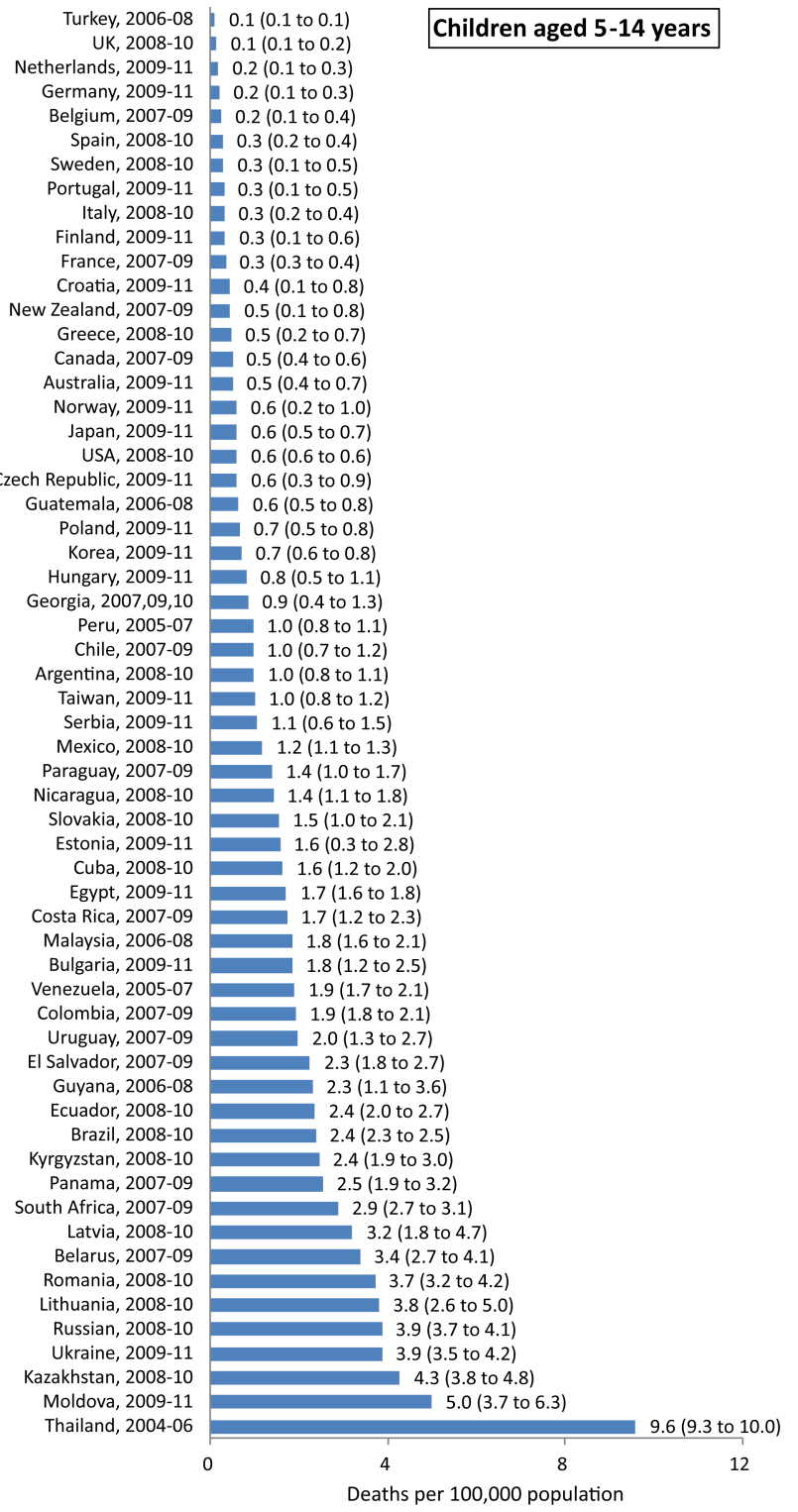

Figure 3 Unintentional drowning mortalty rate (deaths per 100000 population) and $95 \%$ Cls for children aged 5-14 years in each country. water, other, and unspecified). The countries were grouped according to region as used by the GBD 2010 . $^{1}$

\section{RESULTS}

Table 1 presents the ranking of unintentional drowning mortality rate for each country by age groups. Of the 10 countries with highest ranking in age-standardised mortality rates, six (Belarus, Lithuania, Latvia, Russia, Ukraine and Moldova) were in Eastern Europe and two (Kazakhstan and Kyrgyzstan) were in Central Asia. Some countries (Japan, Finland and Greece) had a relatively low rank in mortality rate among children aged $0-4$ years $(43,48$ and 40 , respectively) but had a high rank in mortality rate among older adults (1, 9, and 4 respectively). On the contrary, South Africa and Colombia had a relatively high rank among children aged 0-4 years (7 and 9) but had a relatively low rank in mortality rate among older adults (25 and 31). The numbers, proportions and rates of unintentional drowning deaths in each country are illustrated by age and region in online supplementary file 1 .

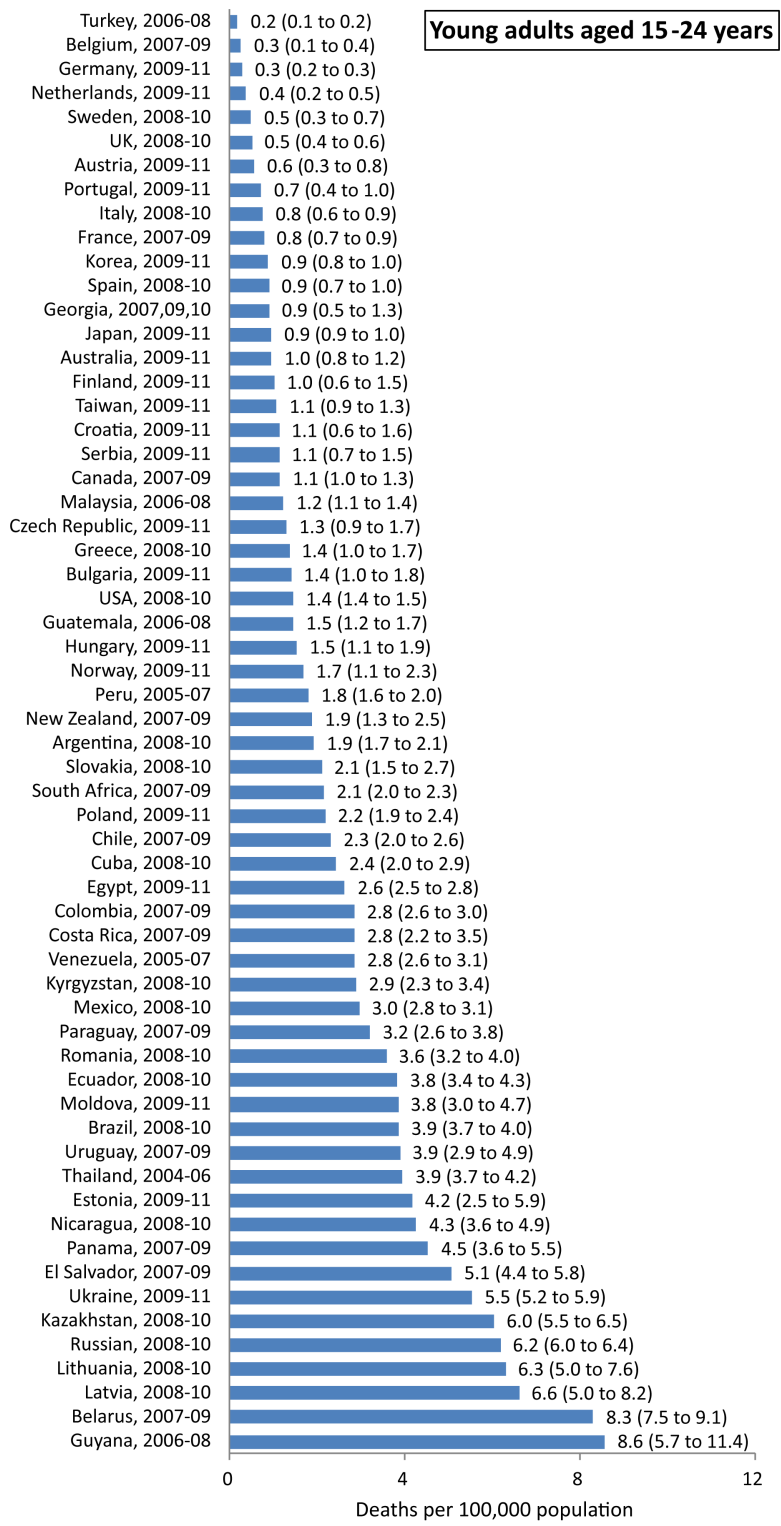

Figure 4 Unintentional drowning mortalty rate (deaths per 100000 population) and $95 \%$ Cls for young adults aged 15-24 years in each country. 
The age-standardised and age-specific unintentional drowning mortality rate and 95\% CI in each country are illustrated in figures 1-7. The range in mortality rate between countries with highest and lowest rates was largest among children aged 0-4 years, and was lowest among young adults aged 1524 years, and middle adults aged $45-64$ years.

Of the 54 countries that used ICD-10 detailed Three or Four Character List codes (see online supplementary file 2), only 14 countries provided high-quality information on body of water and mechanism of drowning, that is, with less than $20 \%$ classified as unspecified (table 2). The proportion of unintentional drowning deaths involving bathtubs was extremely high in Japan (65\%), compared to the second and third highest, Canada (11\%), and the USA (11\%). Of the 13634 drowning deaths involving bathtubs in Japan between 2009 and 2011, 12 $038(88 \%)$ were older adults aged 65 years or above. The proportion involving natural water was high in Finland (93\%), Panama (87\%), and Lithuania (85\%). The percentage involving swimming pools was high in the USA (18\%), Australia (13\%), and New Zealand (7\%).

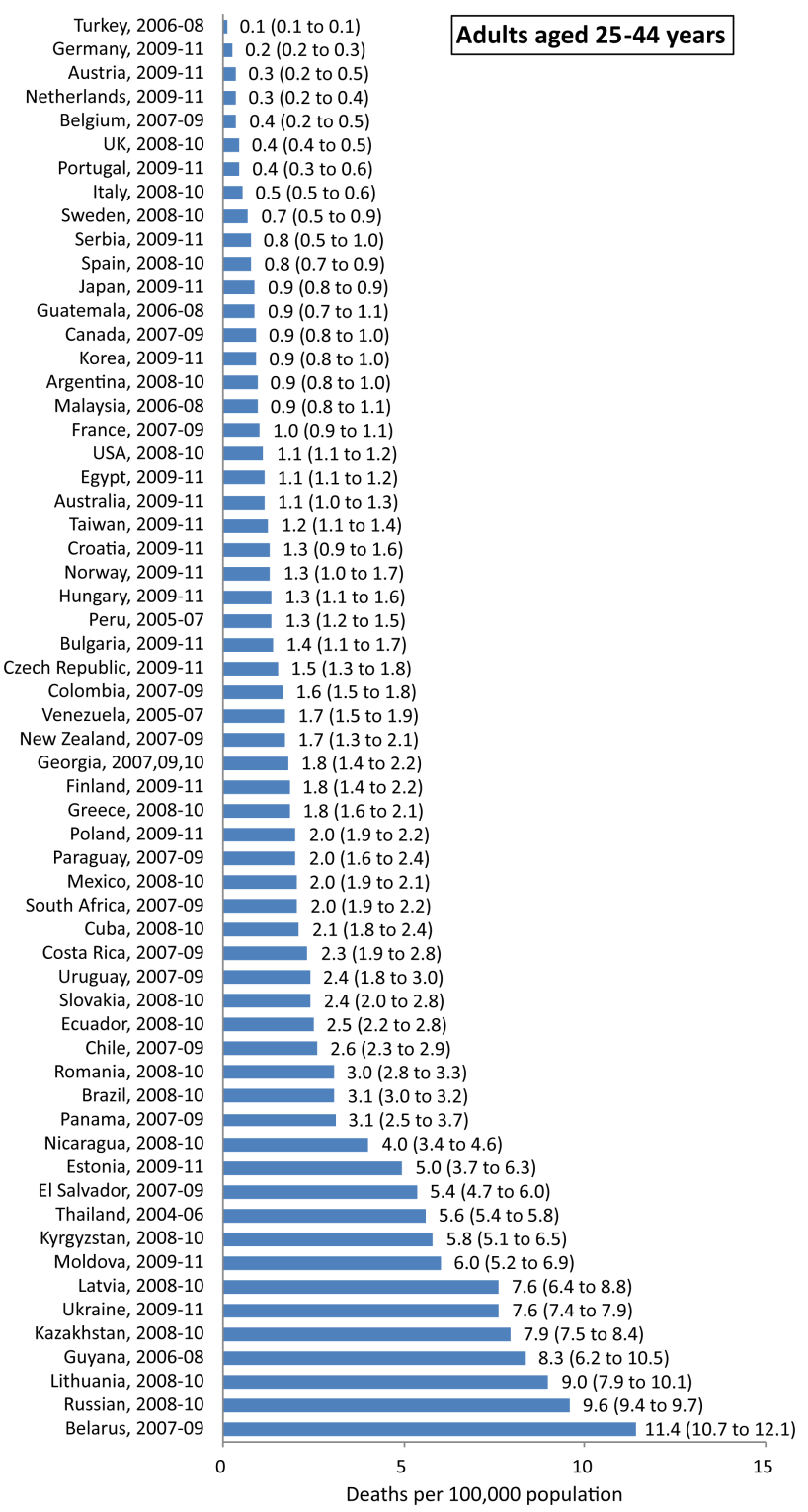

Figure 5 Unintentional drowning mortalty rate (deaths per 100000 population) and $95 \%$ Cls for adults aged $25-44$ years in each country.
Of the 2088 drowning deaths occurring in swimming pools in the USA between 2008 and 2010, 766 (37\%) were children aged $0-4$ years, $244(12 \%)$ were children aged $5-14$ years, 163 (8\%) were young adults aged 15-24 years, 264 (13\%) were adults aged 25-44 years, 319 (15\%) were middle adults aged 45-64 years, and $332(16 \%)$ were older adults aged 65 years and above. With regard to the mechanism of drowning in swimming pools in the USA, the proportion that involved falling into water was $18 \%$ (141/766) among children aged $0-4$ years, 7\% (17/244) among children aged 5-14 years, 4\% (6/163) among young adults aged 15-24 years, 5\% (13/264) among adults aged 25-44 years, 7\% (23/319) among middle adults aged 4564 years, 21\% (70/332) among older adults aged 65 years and above.

\section{DISCUSSION}

The findings of this study suggest huge variations in unintentional drowning mortality rates and relative involvement of different bodies of water across countries. We found a more than

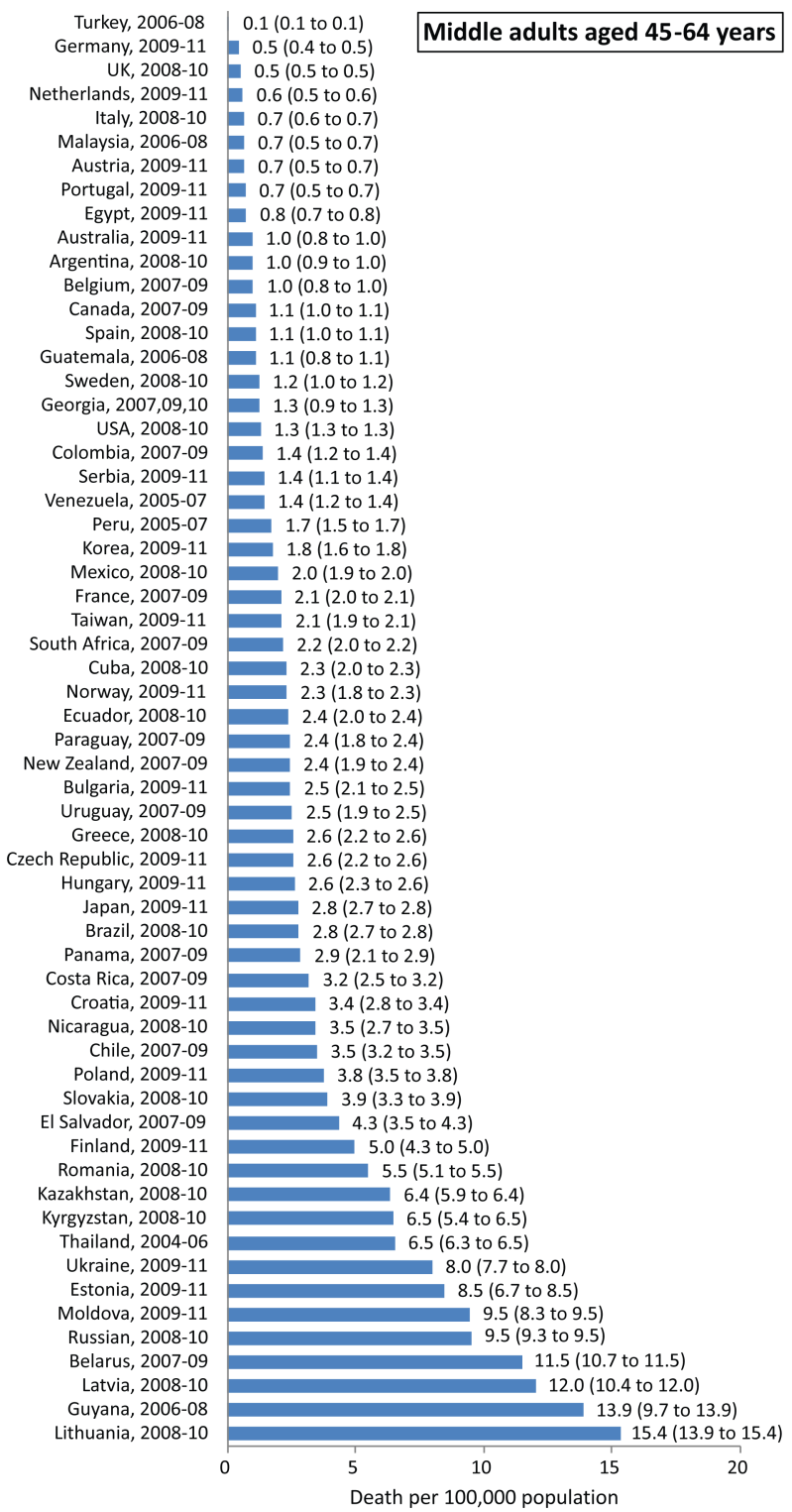

Figure 6 Unintentional drowning mortalty rate (deaths per 100000 population) and $95 \%$ Cls for middle adults aged $45-64$ years in each country. 


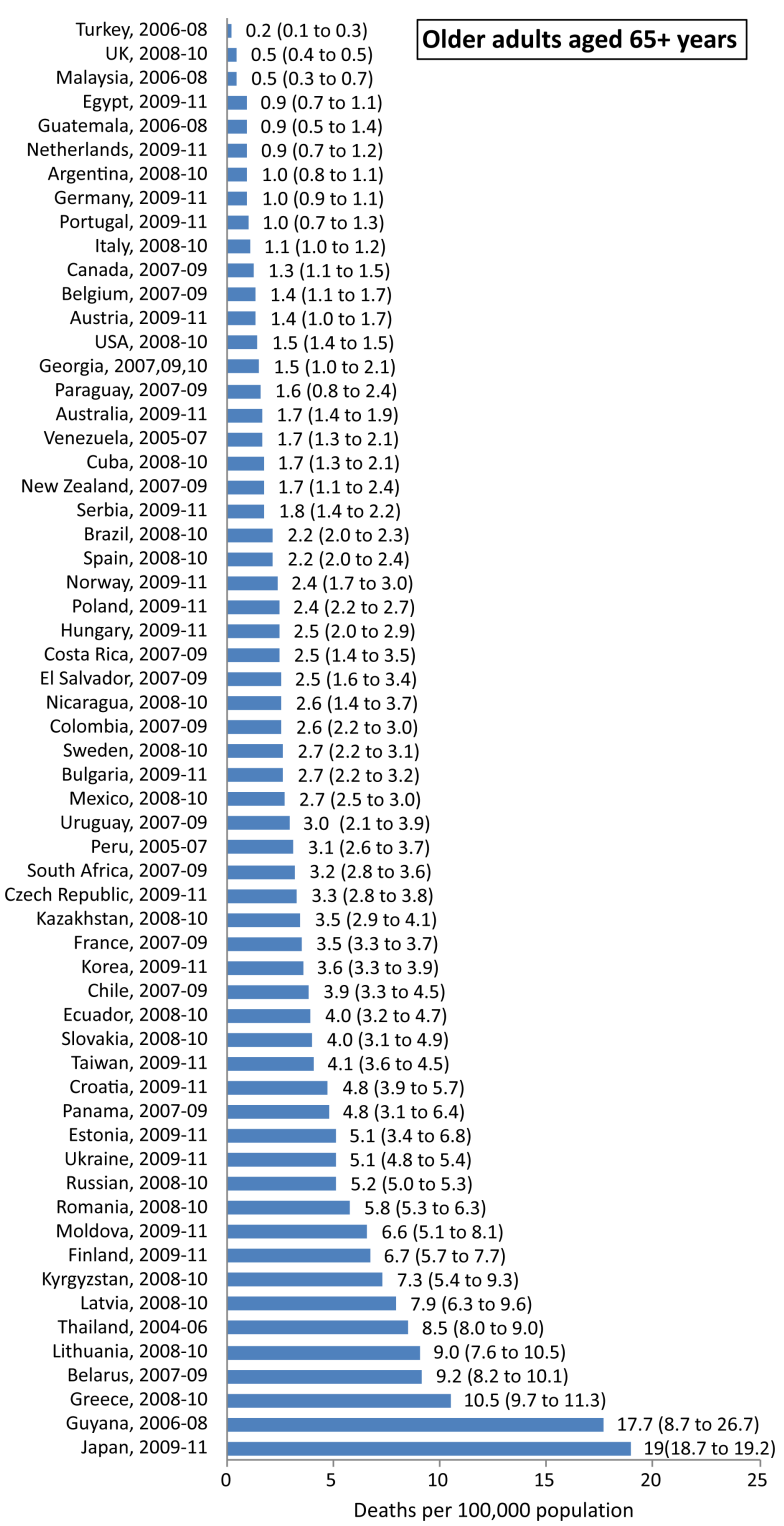

Figure 7 Unintentional drowning mortalty rate (deaths per 100000 population) and $95 \%$ Cls for older adults aged 65 years and above in each country.

20 times difference in highest and lowest age-standardised mortality rates between countries. Countries in Eastern Europe and Central Asia had comparatively high mortality rates. Japan had an extremely high mortality rate among older adults involving bathtubs. The USA had the highest relative proportion involving swimming pools.

We should be cautious regarding the comparability of mortality data across countries due to variable completeness and coverage. The GBD 2010 study stressed that completeness of mortality data is often substantially different for child and adult deaths; while in some regions, such as Latin America, child completeness is usually lower than adult completeness, alternate patterns are observed in Asia. Some systems capture deaths relatively completely in selected administrative units only, such as in Turkey. Therefore, completeness of registration might be high but coverage is not. ${ }^{1}$ The findings of this study indicate that mortality rate in Turkey was lowest in each age group, which might be due to poor coverage reporting drowning deaths.

Most unintentional drowning events occurred in communities with natural water such as seas, rivers, lakes and ponds; subsequently, the victims are found dead at the scene many hours after the drowning event occurred. Many of these drowned corpses are not brought to hospitals or health facilities and, therefore, are under-recognised. Furthermore, societal factors ranging from financial consideration, to fear of punitive legal implications for the persons reporting the drowning, to distance to health facilities, and lack of transportation all may be factors that impede reporting. According to UNICEF survey, estimation of child drowning in low and middle-income countries in Asia, around 20\% of child drowning deaths were underrecognised in all countries surveyed. ${ }^{20}$

Of the 10 countries with the highest age-standardised mortality rates estimated in this study, Guyana and Thailand had completeness levels less than 90\%. For the other eight countries, two were in Central Asia (Kazakhstan and Kyrgyzstan) and six were in Eastern Europe (Belarus, Latvia, Lithuania, Moldova, Russia, and Ukraine). Six of these are members of or participate in the Commonwealth of Independent States, where it has been suggested that the increasing injury mortality rates are a consequence of poor management of the societal transition to market economies. Furthermore, there are high rates of alcohol consumption, which is an obvious risk factor for unintentional injuries. ${ }^{29}$ However, no study yet has specifically examined the exact circumstances of unintentional drowning deaths in Eastern European countries, and the potential connection to alcohol consumption.

We should also consider the quality of reporting for specific information on death certificates across counties. We defined high quality of reporting as less than $20 \%$ of drowning deaths classified as unspecified for body of water or mechanism of drowning. According to this definition, only 17 out of 69 countries (25\%) using ICD-10 detailed Three or Four Character List codes submitted high-quality drowning-related mortality data to WHO in $2009 .{ }^{30}$ In 2003, the number of countries with highquality mortality data was 14 out of 54 (26\%), not a significant change.

Of the 14 countries with high quality in reporting information on body of water in this study, natural water was the main body of water involved in unintentional drowning deaths in 13 countries. The only exception was Japan, where bathtub was the main body of water involved and victims were mostly older adults. Researchers in Japan pointed out the low autopsy rates for elderly deaths involving bathtubs and suggested that many of the so-called drowning deaths were actually due to ischaemic heart disease or cerebrovascular disease. They also found variation in personal preferences of medical examiners, police surgeons, and general practitioners for certifying drowning deaths versus cardiovascular diseases deaths. ${ }^{31} 32$

There is no specific subcategory under natural water. Previous studies have indicated that the main type of natural water differed across countries. The type of natural water most often involved was, lake, in Finland; sea, in Denmark, ${ }^{4}$ Australia, ${ }^{6}$ Singapore, ${ }^{10}$ northern Iran $^{15}$ and urban South African ${ }^{18}$; pond/ ditch, in rural Bangladesh, ${ }^{5}$ China ${ }^{13}$ and south India. ${ }^{14}$ The variations are due to geographic environment, climate and cultural activities, which influence circumstances that may result in drowning.

There were two countries with a relatively high proportion of drowning in swimming pools: the USA (18\%) and Australia (13\%). A US study of swimming pool drowning deaths among residents aged 5-24 years indicated that the majority of Black victims $(51 \%)$ drowned in public pools, the majority of White victims (55\%) drowned in residential pools, and the majority of Hispanic victims (35\%) drowned in neighbourhood pools. ${ }^{33}$ 


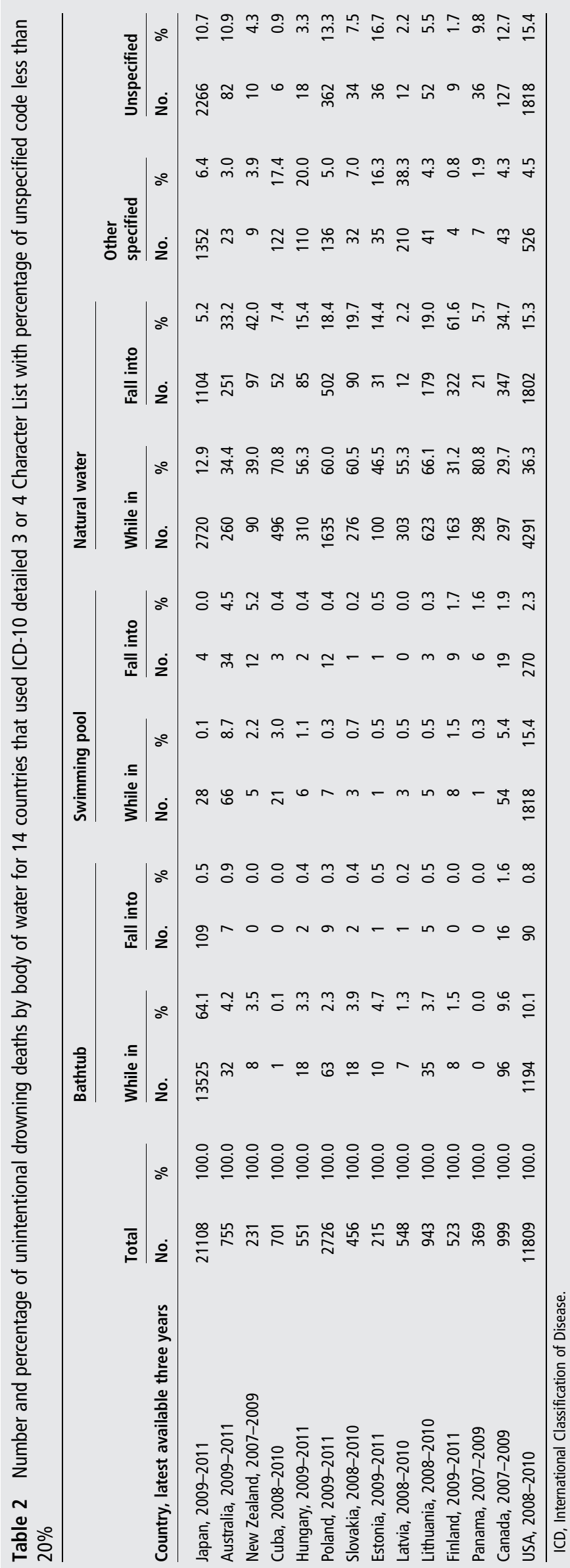

Our findings point out that one-third of swimming pool drowning deaths were middle and older adults. However, no study yet has examined circumstances surrounding swimming pool drowning among middle and older adults. We also found that children and older adults were the age groups with highest percentage, with falling into water as the mechanism involved. Further studies are needed to collect relevant information on drowning deaths involving falling into water in a swimming pool, for designing better preventive measures.

Several other limitations should be noted. First, many countries with high drowning mortality rates (eg, India and Bangladesh) were not included because no data were available in the WHO mortality database. Second, to ensure statistical power stability, we confined our analysis to countries that reported more than 150 deaths by drowning with the most recent year of data after 2005, which resulted in 93 countries being excluded from the analysis (including China). Third, for countries using condensed ICD-9 Basic Tabulation List or condensed ICD-10 Tabulation List, we could not identify water transport-related drowning deaths (ie, ICD-9 code E830 and E832 and ICD-10 code V90 and V92).

Despite these limitations, this preliminary descriptive epidemiological study can still provide useful information as a starting point for further in-depth investigations within individual countries. After considering the completeness of reporting and quality of classifying drowning deaths across countries, we conclude that drowning is a high-priority public health problem in Eastern Europe, Central Asia, Japan (older adults involving bathtubs), and the USA (involving swimming pools). Further in-depth studies are needed to explore the exact circumstances and specific factors as basic information in designing relevant counter-measures.

\section{What is already known on the subject}

- Most previous studies on unintentional drowning mortality were confined to one country and focused on children.

- Little is known with regard to drowning mortality rates for middle-aged and older adults, with a global picture.

\section{What this study adds}

- Age-standardised drowning mortality rates were highest in countries in Eastern Europe and Central Asia.

- Older adults in Japan had an extremely high drowning mortality rate involving bathtubs.

- The proportion of drowning deaths in swimming pools was highest in the USA. Children and older adults had high percentages of falling into swimming pools.

Acknowledgements The authors thank Ms. Bai-Huan Lin for her analyses of data.

Collaborators Tsung-Hsueh Lu.

Contributors C-YL, Y-FW and T-HL conceived the study, guided the analyses, wrote the article draft and are the guarantors of the study. IK interpreted the results and critically revised the manuscript. 
Funding This study was funded by the Department of Health of Taiwan (DOH101Z3087), the National Science Council (NSC102-2314-B-006-054) and the Chi-Mei \& National Cheng Kung University Joint Program (CMNCKU10016).

Competing interests None.

Patient consent No.

Ethics approval This study was approved by the Institutional Review Boards of Chi-Mei Medical Center (09909-004) and National Cheng Kung University Hospital (ER-99-170).

Provenance and peer review Not commissioned; externally peer reviewed.

Data sharing statement The data used in this study are accessible from website of the WHO Health Statistics and Health Information Services.

Open Access This is an Open Access article distributed in accordance with the Creative Commons Attribution Non Commercial (CC BY-NC 4.0) license, which permits others to distribute, remix, adapt, build upon this work non-commercially, and license their derivative works on different terms, provided the original work is properly cited and the use is non-commercial. See: http://creativecommons.org/ licenses/by-nc/4.0/

\section{REFERENCES}

1 Lozano R, Naghavi M, Foreman K, et al. Global and regional mortality from 235 causes of death for 20 age groups in 1990 and 2010: a systematic analysis for the Global Burden of Disease Study 2010. Lancet 2012;380:2095-128.

2 Barss P, Smith GS, Baker SP, et al. Unintentional injuries: drownings, falls, and burns. In: Barss P, Smith GS, Baker SP, Mohan D. eds Injury prevention: an international perspective. New York: Oxford University Press, 1998:153.

3 Brenner RA, Taneja G. Injury prevention: drowning. Rivara F, tpic ed. In: Tremblay RE, Boivin M, Peters RdeV. eds Encyclopedia on early childhood develpment [online]. Montreal, Quebec: Centre of Excellence for Early Childhood Develpment and Strategic Knowledge Cluster on Early Child Deveopment, 2010:1-6.

4 Steensberg J. Epidemiology of accidental drowning in Denmark 1989-1993. Acc Anal Prev 1998;30:755-62.

5 Ahmed MK, Rahman M, van Ginneken J. Epidemiology of child deaths due to drowning in Matlab, Bangladesh. Int J Epidemiol 1999;28:306-11.

6 Mackie IJ. Patterns of drowning in Australia, 1992-1997. Med J Aust 1999;171:587-90.

7 Brenner RA, Trumble AC, Smith GS, et al. Where children drown, United States, 1995. Pediatrics 2001;108:85-9.

8 Quan L, Cummings P. Characteristics of drowning by different age groups. Inj Prev 2003;9:163-68.

9 Browne ML, Lewis-Michl EL, Stark AD. Unintentional drowning among New York State residents, 1988-1994. Public Health Rep 2003;118:448-58.

10 Tan RM. The epidemiology and prevention of drowning in Singapore. Singapore Med J 2004;45:324-29.

11 Lunetta P, Smith GS, Penttilä A, et al. Unintentional drowning in Finland 19702000: a population-based study. Int J Epidemiol 2004;33:1053-63.

12 Capkova M, Veleminsky M, Benesova V, et al. Monitoring of drowning and near-drowning in the Czech Republic in the year 2001-2002. Int J Inj Contr Saf Prom 2006;13:43-5.

13 Fang Y, Dai L, Jaung MS, et al. Child drowning deaths in Xiamen city and suburbs, People's Republic of China, 2001-5. Inj Prev 2007;13:339-43.

14 Shetty BSK, Shetty M. Epidemiology of drowning in Mangalore, a coastal Taluk of South India. J Forensic Legal Med 2007;14:410-5.
15 Kiakalayeh AD, Mohammadi R, Ekman DS, et al. Unintentional drowning in northern Iran: a population-based study. Acc Ana Prev 2008;40:1977-81.

16 Rahman A, Mashreky SR, Chowdhury SM, et al. Analysis of the childhood fatal drowning situation in Bangladesh: exploring prevention measures for low-income countries. Inj Prev 2009;15:75-9.

17 Jagnoor J, Bassani DG, Keay L, et al. Unintentional injury deaths among children younger than 5 years of age in India: a nationally representative study. Inj Prev 2011;17:151-5.

18 Donson $\mathrm{H}$, van Niekerk $\mathrm{A}$. Unintentional drowning in urban South Africa: a retrospective investigation, 2001-2005. Int J Inj Contr Saf Prom 2013;20:218-26.

19 Peden MM, McGee K. The epidemiology of drowning worldwide. Inj Contr Saf Prom 2003;10:195-99.

20 Linnan M, Rahman A, Scarr J, et al. Child drowning: evidence for a newly recognized cause of child mortality in low and middle income countries in Asia. Working Paper 2012-07, Special Series on Child Injury No. 2. Florence: UNICEF Office of Research, 2012

21 Smith GS, Langlois JA, Rockett IRH. International comparisons of injury mortality: hypothesis generation, ecological studies, and some data problems. Proceedings of the International Collaborative Effort on Injury Statistics. Volume 1. Hyattsville, MD: National Center for Health Statistics, 1995;13:1-15. (DHHS publication No (PHS) 95-1252).

22 Langlois JA, Smith GS, Baker SP, et al. International comparisons of injury mortality in the elderly: issues and differences between New Zealand and the United States. Int J Epidemiol 1995;24:136-43.

23 Hijar M, Chu LD, Kraus JF. Cross-national comparison of injury mortality: Los Angeles County, California and Mexico City, Mexico. Int J Epidemiol 2000;29:715-21.

$24 \mathrm{Lu}$ TH, Chiang TL, Lynch JW. What can we learn from international comparisons of social inequalities in road traffic injury mortality? Inj Prev 2005;11:131-3.

25 World Health Organization. Download the raw data files of the WHO Mortality Database. 2 February 2014. http://www.who.int/healthinfo/statistics/mortality_ rawdata/en/index.html

26 Mathers C, Stevens G, Ma Fat D. WHO methods and data sources for global causes of death, 2000-2011. Geneva: Department of Health Statistics and Information Systems, World Health Organization, 2013.

27 Bhalla K, Harrison JE, Shahraz S, et al. the Global burden of disease injury expert group. Availability and quality of cause-of-death data for estimating the global burden of injuries. Bull World Health Organ 2010;88:831-8.

28 The Population Division of the United Nations Department of Economic and Social Affairs. The 2010 Revision of the World Population Prospects. 2 February 2014. http://esa.un.org/unpd/wpp/

29 Hyder AA, Aggarwal A. The increasing burden of injuries in Eastern Europe and Euroasia: making the case for safety investments. Health Policy 2009;89: $1-13$.

30 Lu TH, Lunetta P, Walker S. Quality of cause-of-death reporting using ICD-10 drowning codes: a descriptive study of 69 countries. BMC Med Res Methodol 2010;10:30.

31 Yoshioka N, Nibe H, Enzan K, et al. Sudden death in the bathroom and its medico-legal issues. Res Pract Forensic Med 1998;41:353-9. (in Japanese).

32 Kurosaki K, Kuriiwa F, Hara S, et al. Questionable diagnoses on the cause of death while bathing. Res Pract Forensic Med 2002;45:175-80. (in Japanese).

33 Saluja G, Benner RA, Trumble AC, et al. Swimming pool drownings among US residents aged 5-24 years: understanding racial/ethic disparities. Am J Public Health 2006;96:728-33. 